\title{
В.А. Лазарев ${ }^{1 *}$, Е.Г. Мирошникова ${ }^{1}$
}

'уральский государственный экономический университет, г. Екатеринбург, Российская Федерация, *e-таil: lazarev.eka@gmail.com

Ключевые слова:

качество питьевой

воды;

мембранная

технология;

водоподготовка;

деминерализация;

кондиционирование воды

\begin{abstract}
Реферат
Предложена и испытана компоновка обратноосмотической установки производительностью 10 л/ч для финальной очистки холодной водопроводной воды с возможностью изменения минерального состава очищенной воды. Актуальность разработки обусловлена как глобальным техногенным загрязнением биосферы, так и изношенностью городских сетей водоснабжения. С использованием современных методов водоподготовки создана многоступенчатая мембранная система, позволяющая удалять из воды механические, химические и микробиологические загрязнения. На завершающем этапе качество и органолептические свойства очищенной воды улучшаются за счет использования постфильтра и минерализатора. В течение годичного цикла эксплуатации экспериментально подтверждены стабильность работы оборудования и соответствие характеристик получаемого продукта как требованиям российских регламентов, так и нормам Всемирной организации здравоохранения. Показатели качества и безопасности воды исследованы на соответствие СанПиН 2.1.4.1074-01 «Питьевая вода. Гигиенические требования к качеству воды централизованных систем питьевого водоснабжения. Контроль качества». Замеры общего солесодержания воды показали, что оно снижается от $200 \pm 20$ мг/л в исходной воде до $22 \pm 2$ мг/л в очищенной и кондиционированной воде (при рекомендуемой норме не более 50 мг/л).
\end{abstract}

\section{Membrane Installation Development for Post-Treatment and Conditioning of Drinking Tap Water according to the World Health Organization Standards}

\author{
Vladimir A. Lazarev' ${ }^{*}$, Elena G. Miroshnikova ${ }^{1}$ \\ 'Ural State University of Economics, Ekaterinburg, Russian Federation, *e-mail: lazarev.eka@gmail.com
}

Keywords:

drinking quality water; membrane technology; water preparation; demineralization; water condition

\section{Abstract}

Authors introduced and tested the layout of reverse-osmosis production plant for final purification of cold tap water with a capacity of $10 \mathrm{l} / \mathrm{h}$ with the possibility of changing the purified water mineral composition. The development relevance is due to both global anthropogenic pollution of the biosphere and the deterioration of urban water supply networks. Authors developed a multi-stage membrane system using modern methods of water treatment to remove mechanical, chemical and microbiological contamination from the 
water. At the final stage, a man improved the quality and organoleptic properties of the purified water using the "post-filter mineralizer" production plant. Research confirmed the equipment stability and the characteristics compliance of the resulting product with both the requirements of Russian regulations and the norms of the World Health Organization experimentally during the one-year operation cycle. Authors scrutinized water quality and safety indicators on the basis of SanPiN 2.1.4.1074-01 "Drinking water. Hygienic Requirements for Water Quality of Centralized Drinking Water Supply Systems. Quality Control». Measurements of the total water salinity showed that it decreased from $200 \pm 20 \mathrm{mg} / \mathrm{l}$ in the source water to $22 \pm 2 \mathrm{mg} / \mathrm{l}$ in purified and conditioned water (at the recommended rate of not more than $50 \mathrm{mg} / \mathrm{l}$ ).

For citation: Vladimir A. Lazarev, Elena G. Miroshnikova. Membrane Installation Development for Post-Treatment and Conditioning of Drinking Tap Water according to the World Health Organization Standards. Индустрия numaнuя/Food Industry. 2018. T. 4, № 3. Pp. 43-51. DOI 10.29141/2500-1922-2019-4-3-5

\section{Введение}

Одна из глобальных мировых проблем - нехватка чистой пресной воды-уже ощущается и в России, особенно в крупных городах. Основные причины такого положения - рост потребления «голубого золота» на нужды промышленности и сельского хозяйства, с одной стороны, и антропогенное загрязнение всех компонентов окружающей среды - с другой. Так, по данным отечественных специалистов, только 40 \% россиян пьют воду, отвечающую санитарным нормам, т. е. вода из водопроводной сети зачастую не соответствует показателям качества и безопасности, а следовательно, негативно влияет на здоровье человека $[1 ; 2 ; 3 ; 4]$.

На централизованных станциях водоподготовки с целью очистки воды, поступающей из источников водозабора, используют комплекс механических, биологических, химических, физико-химических методов [5; 6; 7; 8]. Однако для удаления различных видов загрязнений довольно часто применяют реактивы, являющиеся токсичными веществами (например, коагулянты и хлор относятся к третьему классу опасности). МУП «Водоканал» (г. Екатеринбург) для реагентной обработки воды в качестве коагулянта использует оксихлорид алюминия «Бопак-Е», а для проведения флокуляции - порошкообразный «Праестол - 650TR». По данным, полученным от производителя продукта, «Преастол» является высокомолекулярным электролитом на основе акриламида. Как известно, акриламид и его производные проявляют сильные нейротоксичные свойства, т. е. действуют на нервную систему при любом пути поступления в организм человека, и, кроме того, это вещество отрицательно воздействует на печень и почки.

Еще одна «болезнь» российского водоснабжения - физическое состояние трубопроводных и канализационных сетей. Согласно исследовани- ям Ассоциации водоснабжения и водоотведения в большинстве крупных городов России водопровод изношен более чем на $50 \%$, что приводит к вторичному загрязнению питьевой водопроводной воды. Даже качественно подготовленная на специализированных станциях вода подается потребителю по старым, проржавевшим трубам, причем не исключено частичное смешивание питьевого и канализационного потоков. Отсюда очевидная необходимость дополнительной очистки воды непосредственно конечным потребителем - населением или предприятиями общественного питания. Чаще всего для решения данной задачи применяют различные фильтрационные установки.

Питьевую воду I категории можно получить с помощью ступенчатой схемы фильтрования высшей степени очистки с мембранной фильтрацией - системой обратного осмоса, через фильтры с ультрафильтрационной мембраной, нанофильтрационные модули. Такие системы применяются в установках глубокой очистки воды, основными элементами которых являются обратноосмотические мембраны, способные не только очищать воду от загрязнений солями тяжелых металлов, от пестицидов, гербицидов, нитратов, от вирусов и бактерий, но и сбалансировать ее минеральный состав $[6 ; 9 ; 10]$.

Цель работы - исследование качества воды в системе холодного водоснабжения г. Екатеринбурга и создание малогабаритной (малоразмерной) установки (системы) для ее доочистки и нормализации минерального состава в соответствии с требованиями СанПиН 2.1.4.1074-01 «Питьевая вода. Гигиенические требования к качеству воды централизованных систем питьевого водоснабжения. Контроль качества» и нормами, рекомендуемыми Всемирной организацией здравоохранения. 
0бъекты и методы исследования

В процессе изучения работы пилотной установки исследовали пробы воды, отбираемые в трех точках:

проба № 1 (исходная) - на входе в систему, т. е. собственно водопроводная вода сетей холодного водоснабжения;

проба № 2 - после очистки с использованием обратноосмотической системы;

проба № 3 - на выходе из установки.

Отбор образцов воды для исследований осуществляли в соответствии с ГОСТ 31861-2012 «Вода. Общие требования к отбору проб», ГОСТ 31942-2012 «Вода. Отбор для микроскопического анализа", ГОСТ Р 56237-2014 (ИСО 5667 - 5: 2006) «Вода питьевая. Отбор проб на станциях водоподготовки и в трубопроводных распределительных системах».

Измерение значений $\mathrm{pH}$ производили потенциометрическим методом с помощью прибора pH-meter pH-410, оснащенного комбинированным стеклянным рН-электродом ЭСК-1, с применением методики выполнения измерений, рекомендованной ПНД Ф 14.1:2:3:4.121-97.

Для измерения окислительно-восстановитель-

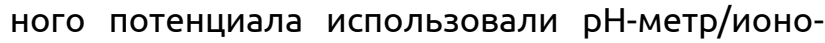
мер «ТА-Ион» (ООО «НПП «Томьаналит»», г. Томск, Россия) с применением стандартной двухэлектродной ячейки. Индикаторным электродом и электродом сравнения являлись платиновый дисковый (диаметр 2 мм) электрод в корпусе из полиэфиркетона (Metrohm AG, Швейцария) и ЭВЛ-1М3.1 (ОАО «Гомельский завод измерительных приборов», Республика Беларусь) с системой сравнения $\mathrm{Ag} / \mathrm{AgCl}, 3,5 \mathrm{M} \mathrm{KCl}$ соответственно.

Определение содержания ионов меди, свинца и кадмия производили методом амальгамной инверсионной вольтамперометрии с использованием полуавтоматического компьютеризированного вольтамперометрического анализатора «ИВА-5» (НПВП «ИВА», г. Екатеринбург, Россия). Для выполнения анализа использовали трехэлектродную ячейку объемом 10 мл со стеклоуглеродным стержнем в качестве вспомогательного электрода и хлоридсеребряным электродом сравнения $(\mathrm{Ag} / \mathrm{AgCl}, 3,5 \mathrm{M} \mathrm{KCl})$ (г. Гомель, Республика Беларусь). Индикаторным электродом служил модифицированный каломелью толстопленочный углеродсодержащий электрод МТУЭ (НПВП «ИВА», г. Екатеринбург, Россия).

Использование электродов данного типа позволяет проводить электрохимические исследования образцов различных водных объектов без проведения пробоподготовки $[11 ; 12]$.

Для изучения химических характеристик воды использовали метрологически аттестованные методики количественного анализа в соответствии с ГОСТ Р 51232-98 «Вода питьевая. Общие требования к организации и методам контроля качества».

Общую жесткость воды оценивали методом комплексонометрического титрования с индикатором хромогеном черным по ГОСТ 31954-2012 «Вода питьевая. Метод определения общей жесткости». В соответствии с данным методом в качестве рабочего раствора используют динатриевую соль этилендиаминтетрауксусной кислоты (трилон Б), которая в присутствии аммонийного буфера образует с содержащимися в пробе ионами кальция и магния прочное комплексное соединение, при этом в точке эквивалентности наблюдается переход винно-красной окраски титруемого раствора в сине-фиолетовую.

Оценку перманганатной окисляемости проб воды проводили по ГОСТ Р 55684-2013 (ИСО 8467:1993) «Вода питьевая. Метод определения перманганатной окисляемости». Сущность данного метода заключается в окислении органических и неорганических веществ, присутствующих в пробе анализируемой воды, заданным количеством перманганата калия в сернокислой среде в процессе нагревания, последующем добавлении оксалат-иона в виде раствора оксалата натрия (способ А) или раствора щавелевой кислоты (способ Б) и титровании его избытка раствором перманганата калия.

Показатель перманганатной окисляемости в пересчете на атомарный кислород определяется по количеству пошедшего на титрование перманганата калия.

Все химические и физико-химические исследования в лаборатории Уральского государственного экономического университета проводились при температуре $23 \pm 3^{\circ} \mathrm{C}$.

Независимые исследования проб выполнялись в филиале Центра гигиены и эпидемиологии в Свердловской области в Чкаловском районе города Екатеринбурга, в городе Полевском и Сысертском районе.

\section{Результаты исследования и их обсуждение}

В зависимости от первоначальных характеристик воды традиционные методы водоподготовки на станциях централизованного водоснабжения включают в себя несколько этапов: отстаивание, обеззараживание, коагуляция, умягчение, осветление, аэрация, деминерализация, фильтрация. Так, МУП «Водоканал» г. Екатеринбурга осуществляет двухступенчатый процесс очистки сырой воды с предварительным коагулированием, отстаиванием, фильтрованием, обеззараживанием, что позволяет достичь соответствия параметров воды санитарно-гиги- 
еническим нормам. Однако качество воды может значительно снижаться при прохождении по старым, проржавевшим коммуникациям. Вопрос доочистки в точках финального водоразбора остается актуальным. Грамотно подобранное оборудование гарантирует соответствие воды нормативным требованиям и даже делает ее 6олее полезной для здоровья.

В лаборатории технологических машин и оборудования кафедры пищевой инженерии УрГЭУ разработана и смонтирована малогабаритная мембранная установка очистки и кондиционирования водопроводной питьевой воды (рис. 1). Bсе её компоненты - стандартные изделия, широко представленные на рынке оборудования для систем очистки воды.

Установка в миниатюре воспроизводит процессы, выполняемые на станциях водоподготовки.

В открытом положении кран (1) проводит поток воды через модуль грубой очистки (2), предназначенный для удаления возможных макроскопических загрязнений - песка, ржавчины, глины и других твердофазных компонентов (Pentek P5, тонкость фильтрации - 5 микрон). Затем вода проходит через угольный фильтр продольного потока (3), в котором основным рабочим веществом является активированный уголь (Pentek GAC-10). На этой стадии вода очищается от посторонних запахов, мутности, а также от некоторых видов микроорганизмов. Далее вода проходит через фильтр тонкой очистки (4) для удаления мелкодисперсных загрязнений (Pentek P1, тонкость фильтрации - 1 микрон). Насос (5) повыша- ет давление до 6,5 атм, после чего вода проходит через две параллельно соединенные мембраны (6). Наличие двух мембран позволяет повысить производительность установки примерно в два раза. С помощью обратноосмотических мембран происходит частичная деминерализация, в результате образуются два потока - концентрат и пермеат. Концентрат - это вода с повышенным содержанием минеральных веществ, которую можно использовать для технических нужд, или пустить на рецикл. Пермеат - доочищенная и частично деминерализованная вода со сниженным количеством солей жесткости. Ультрафиолетовая лампа (7) осуществляет бактерицидное воздействие на возможные вирусы и бактерии, содержащиеся в воде. Угольный постфильтр (8) позволяет убрать посторонние запахи. Финальным этапом доочистки является минерализатор на основе кокосовых волокон (9). Вода, проходящая через обогащенный кальцитом кокосовый активированный уголь, насыщается кальцием и магнием, что придает ей приятный свежий вкус.

Необходимость установки минерализатора. При разработке установки изучали и контролировали параметры, нормируемые СанПиН 2.1.4.1074-01, а именно оценивали органолептические свойства образцов, их эпидемиологическую безопасность и химическую безвредность. Последний показатель подразумевает измерение, прежде всего, обобщенных характеристик: водородного показателя, общей минерализации, общей жесткости, перманганатной окисляемости и др.

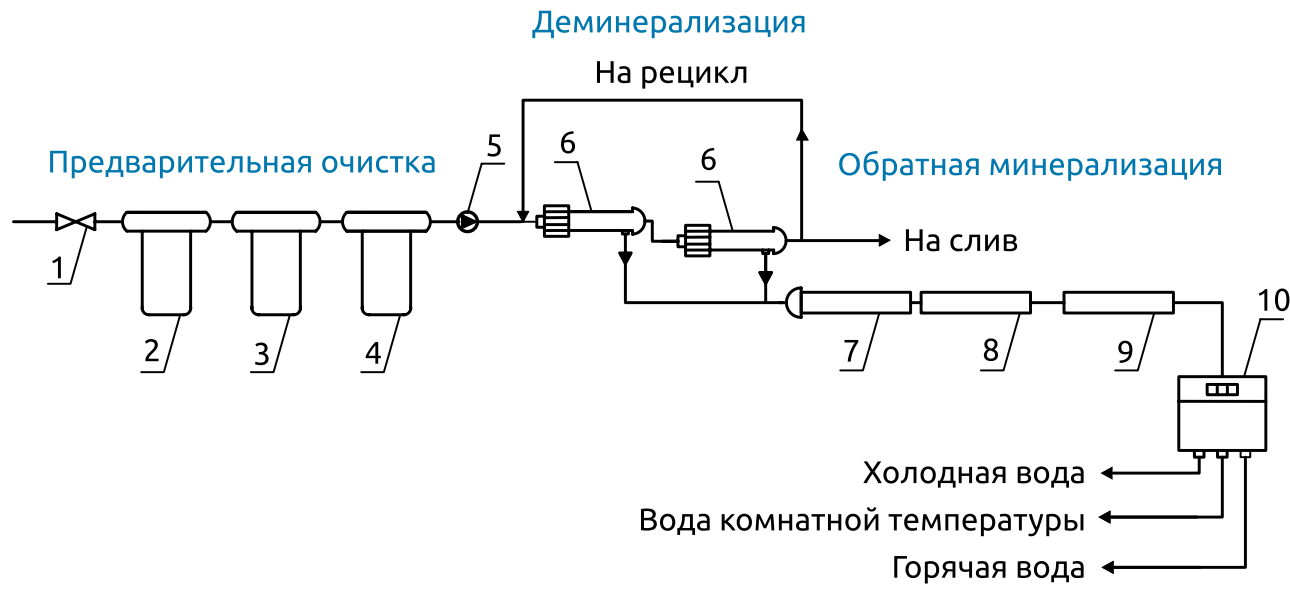

Схема малогабаритной установки очистки водопроводной воды:

1 - вентиль подачи воды; 2 - фильтр грубой очистки; 3 - угольный фильтр продольного потока;

4 - фильтр тонкой очистки; 5 - насос; 6- обратноосмотический мембранный модуль; 7 - ультрафиолетовая лампа;

8 - постфильтр с активированным углем; 9 - картридж-минерализатор; 10 - водораздатчик

Scheme of Small-Sized Tap Water Treatment Plant:

1-Water Supply Valve; 2-Coarse Filter; 3 - Coal Filter of Longitudinal Flow;

4-Fine Filter; 5-Pump; 6-Reverse Osmosis Membrane Module; 7-Ultraviolet Lamp;

8-Activated Carbon Postfilter; 9-Mineralizer Cartridge; 10-Water Dispenser 
Особое внимание уделено процессу контроля за содержанием солей тяжелых металлов, нитратов и нитритов, за уровнем радиоактивности.

Кроме того, нормированы вредные химические вещества, которые поступили или образовались в воде в процессе ее обработки на станциях водоподготовки и в системе водоснабжения: хлор, озон, хлороформ, формальдегид, железои алюминийсодержащие коагулянты и т. д.

Химический состав во многом определяет и органолептические показатели (запах и привкус воды, цветность, мутность), которые также фигурируют в нормативных документах (ГОСТ Р 57164-2016 «Вода питьевая. Методы определения запаха, вкуса и мутности»).

Указанные выше обобщенные показатели могут быть использованы для оперативного контроля и первичной оценки качества питьевой воды по химическому составу. Таким образом, осуществляется мониторинг:

- характера среды водного объекта (кислая, слабокислая, нейтральная, слабощелочная, щелочная);

- общего солесодержания;

- концентрации ионов кальция и магния, определяющих тип жесткости воды: мягкая, средней жесткости, умеренно жесткая, жесткая. Данная характеристика актуальна при потреблении воды населением в питьевых и бытовых целях, для использования в процессах переработки продовольственного сырья и производства пищевых продуктов;

- веществ-восстановителей, в том числе органических. Они способны образовывать крайне вредные для организма человека соединения с хлором. С учетом повсеместного использования на станциях водоподготовки технологии хлорирования воды данный показатель является стратегически важным.

Измерение водородного показателя пробы обычно является приоритетным, поскольку кислотность среды часто влияет на результаты анализа. Значение $\mathrm{pH}$ для исходной пробы водопроводной воды составило 7,4 ед., а после обработки - 6,5 ед., т. е. оба показателя в пределах нормы (СанПиН 2.1.4.1074-01).
Установлено, что исходная проба № 1 имеет общую жесткость 5,8 $\pm 0,1$ ммоль/дм ${ }^{3}$ ( $n=5$, $P=0,95)$ при значении предельно допустимой концентрации 7,0 ммоль/дм³ ${ }^{3}$ При подготовке к титрованию пробы № 2 после введения индикатора раствор окрасился в синий цвет, что можно интерпретировать как свидетельство отсутствия или незначимого присутствия ионов кальция и магния в обработанной пробе. Таким образом, после прохождения мембранной системы вода подвергается деминерализации и становится мягкой, что предпочтительно для производственных и бытовых нужд. Однако использование обедненной по микроэлементам воды в течение длительного времени неблагоприятно для организма человека. Использование минерализатора позволяет повысить содержание биологически ценных солей кальция и магния: при исследовании пробы № 3 их концентрация составила 1,5 $\pm 0,1$ ммоль/дм ${ }^{3}(n=5, P=0,95)$.

Использование мембранной системы позволяет снизить содержание в воде токсичных для человека тяжелых металлов (табл. 1).

Важным показателем качества воды является окисляемость - условная величина, которая характеризует загрязнение воды легкоокисляющимися веществами, главным образом органического происхождения. Она выражается в миллиграммах кислорода, необходимого для окисления загрязнителей, содержащихся в одном литре воды (мг О$\left./ \mathrm{O}_{2} \mathrm{H}_{2} \mathrm{O}\right)$. Вместо кислорода в качестве окислителя в лабораторных условиях применяют раствор перманганата калия, поэтому данный показатель носит название перманганатной окисляемости. Сущность метода состоит в определении количества реагента $\mathrm{KMnO}_{4}$, затраченного на взаимодействие с веществами-загрязнителями пробы (ГОСТ Р 55684-2013 (ИСО 8467:1993) «Вода питьевая. Метод определения перманганатной окисляемости»). Реакция проводится в сернокислой среде в процессе нагревания, после чего к раствору добавляют точно отмеренное количество щавелевой кислоты, избыток которой оттитровывают раствором перманганата калия. В данном случае индикатор для определения конечной точки титрования

Таблица 1. Результаты исследования образцов воды на содержание тяжелых металлов $(n=5, P=0,95)$ Table 1. Research Results of Water Samples for Heavy Metal Content $(n=5, P=0.95)$

\begin{tabular}{|c|c|c|c|c|}
\hline \multirow{2}{*}{$\begin{array}{c}\text { Определяемый } \\
\text { компонент }\end{array}$} & \multicolumn{3}{|c|}{ Содержание компонента, мкг/дм³ } & \multirow{2}{*}{$\begin{array}{c}\text { Класс } \\
\text { опасности }\end{array}$} \\
\hline & Проба № 1 & Проба № 3 & ПДК (ГОСТ СанПиН 2.1.4.1074-01) & \\
\hline $\mathrm{Cu}(\mathrm{II})$ & $16,3 \pm 1,3$ & $1,5 \pm 0,2$ & 1000 & 3 \\
\hline $\mathrm{Pb}(\mathrm{II})$ & $2,8 \pm 0,4$ & $0,20 \pm 0,06$ & 30 & 2 \\
\hline Cd (II) & $\mathrm{H} / \mathrm{O}$ & $\mathrm{H} / \mathrm{O}$ & 1 & 2 \\
\hline
\end{tabular}


Таблица 2. Результаты определения перманганатной окисляемости образцов воды $(n=5, P=0,95)$

Table 2. Results of Permanganate Oxidation Determination of Water Samples $(n=5, P=0.95)$

\begin{tabular}{|l|c|c|}
\hline \multicolumn{1}{|c|}{ Образец } & Значение окисляемости, мг О $/$ л $\mathrm{H}_{2} \mathrm{O}$ & ПДК (СанПиН 2.1.4.1074-01) \\
\hline Холостая проба & $0,42 \pm 0,06$ & \\
\hline Исходная проба № 1 & $4,40 \pm 0,30$ & $5,0 \mathrm{Mr} \mathrm{O}_{2} / \mathrm{H}_{2} \mathrm{O}$ \\
\hline Проба после очистки № 2 & $0,45 \pm 0,03$ & \\
\hline Проба на выходе № 3 & $0,95 \pm 0,04$ & \\
\hline
\end{tabular}

не требуется, поскольку титрант $\mathrm{KMnO}_{4}$ является окрашенным соединением, и при добавлении в процессе титрования одной «лишней» капли весь раствор приобретает розовую окраску.

Важная часть эксперимента - проведение так называемого холостого опыта, когда в качестве пробы используют дистиллированную воду, что позволяет учесть наличие не удаляемых при дистилляции загрязнений.

Данные, полученные в ходе перманганатометрического титрования исследуемых образцов, представлены в табл. 2. Они позволяют сделать вывод о надлежащем качестве водопроводной воды (по химическим показателям) в сетях водоснабжения Ленинского района г. Екатеринбурга. После обработки пробы содержание поддающихся окислению загрязнителей уменьшается до уровня дистиллированной воды.

Интересные результаты (табл. 3) были получены при исследовании окислительно-восстановительного потенциала (ОВП) проб - показателя, который характеризует оксидантную способность воды. Хотя изменение величины ОВП для различных проб небольшое, оно явно отражает

Таблица 3. Результаты определения перманганатной окисляемости образцов воды $(n=5, P=0,95)$

Table 3. Results of Permanganate Oxidation Determination of Water Samples $(n=5, P=0.95)$

\begin{tabular}{|l|c|}
\hline \multicolumn{1}{|c|}{ Образец } & Значение ОВП, мВ \\
\hline Исходная проба № 1 & $350 \div 354$ \\
\hline Проба после очистки № 2 & $377 \div 379$ \\
\hline Проба на выходе № 3 & $333 \div 336$ \\
\hline Проба на выходе № 3 & $0,95 \pm 0,04$ \\
\hline
\end{tabular}

следующую тенденцию: увеличение ОВП в пробе № 2 свидетельствует о том, что при использовании обратноосмотической технологии происходит удаление из воды не только вредных, но и полезных веществ. Использование на заключительной стадии водоподготовки постфильтра-минерализатора позволяет нивелировать этот негативный момент - потенциал в воде на выходе из системы понижается.

С целью проведения независимой оценки экспертами показателей качества и безопасности очищенной питьевой (конечной) воды в термоконтейнер при $4{ }^{\circ} \mathrm{C}$ были отобраны пробы исходной и очищенной воды и отправлены на лабораторные испытания в филиал Центра гигиены и эпидемиологии в Свердловской области в Чкаловском районе города Екатеринбурга, городе Полевском и Сысертском районе. Результаты испытаний представлены в табл. 4-6.

Показатели органолептической оценки проб (табл. 4) исходной водопроводной и очищенной воды соответствовали требованиям СанПиН 2.1.4.1074-01.

Химический анализ воды (табл. 5) показывает, что уровень рН изменился с 7,5 \pm 0,2 до 6,4 \pm 0,2. Слабощелочная реакция исходной водопроводной воды может быть обусловлена применением химических реагентов на станции водоподготовки. После дополнительной очистки на обратноосмотической установке реакция стала более кислой и приблизилась к норме.

Некоторое уменьшение содержания ионов железа подтверждает вывод о частичной деминерализации пробы. Проведенные замеры общего содержания солей в пробах исходной и доочищенной воды с помощью TDS-метра под-

Таблица 4. Органолептический анализ проб воды

Table 4. Organoleptic Analysis of Water Samples

Показатель

Запах, балл

Привкус, балл

Цветность, градус

Мутность, ЕФМ

Результаты испытаний

Допустимый уровень

НД на методы исследований

$$
0
$$

0

Менее 5

Менее 1

\section{2}

2

20

2,6
ГОСТ 3351-74

ГОСТ 3351-74

ГОСТ 31868-2012

ГОСТ 3351-74 
Таблица 5. Результаты химического анализа проб воды

Table 5. Quantitative Chemical Analysis of Water Samples

\begin{tabular}{|c|c|c|c|}
\hline \multirow{2}{*}{ Показатель } & \multicolumn{2}{|c|}{ Результаты испытаний } & \multirow{2}{*}{$\begin{array}{c}\text { Допустимый } \\
\text { уровень }\end{array}$} \\
\hline & Исходная вода & Очищенная вода & \\
\hline Хлороформ, мг/дм³ & - & Менее 0,0015 & 0,2 \\
\hline $\mathrm{pH}$ & $7,5 \pm 0,2$ & $6,4 \pm 0,2$ & $6-9$ \\
\hline Окисляемость перманганатная, мг О $2 /$ дм³ $^{3}$ & - & Менее 0,25 & 5 \\
\hline Марганец (суммарно), мг/дм³ & - & Менее 0,01 & 0,1 \\
\hline Железо (суммарно), мг/дм³ & $0,110 \pm 0,025$ & Менее 0,1 & 0,3 \\
\hline
\end{tabular}

Таблича 6. Микробиологические показатели проб воды

Table 6. Microbiological Parameters of Water Samples

\begin{tabular}{|c|c|c|c|}
\hline Показатель & $\begin{array}{l}\text { Результаты испытаний } \\
\text { про6 № } 1 \text { и № } 3\end{array}$ & $\begin{array}{l}\text { Допустимый } \\
\text { уровень }\end{array}$ & $\begin{array}{l}\text { НД на методы } \\
\text { исследований }\end{array}$ \\
\hline Общее микробное число, КОЕ/мл & 0 & 50 & MУК $4.21018-01$ \\
\hline $\begin{array}{l}\text { Общее число колиформных бактерий, } \\
\text { клеток в } 100 \text { мл }\end{array}$ & Не обнаружено & Отсутствуют & MУК $4.21018-01$ \\
\hline $\begin{array}{l}\text { Термотолерантные колиформные бактерии, } \\
\text { клеток в } 100 \text { мл }\end{array}$ & Не обнаружено & Отсутствуют & MУK 4.2 1018-01 \\
\hline
\end{tabular}

тверждают, что в пробах исходной воды суммарная концентрация растворенных веществ варьировалась от 180 до 220 мг/л, а после очистки снизилась до 20-25 мг/л.

Проанализировав экспериментально полученные данные о содержании растворенных веществ, в том числе с учетом определения солей жесткости, можно сделать вывод: исходная вода из сетей холодного водоснабжения соответствует требованиям СанПиН 2.1.4.1074-01 как в части соблюдения норм общей жесткости (не более 7,0 мг·экв./л), так и норм общей минерализации (не более 1000 мг/л по сухому остатку), и поэтому является безопасной.

Всемирной организацией здравоохранения проведены глубокие исследования влияния минерализации питьевой воды на здоровье человека и выработаны следующие рекомендации: питьевая вода должна оптимально содержать солей кальция от 20 до 80 мг/л, магния - от 10 до $30 \mathrm{Mг/л.} \mathrm{По} \mathrm{показателю} \mathrm{общей} \mathrm{жесткости} \mathrm{(от-}$ дельно) в данных рекомендациях какое-либо значение не предлагается.

По результатам проведенных микробиологических исследований (табл. 6) не выявлено наличие микроорганизмов и бактерий в образцах.

Кроме вывода об эпидемиологической безопасности питьевой воды в водопроводной системе г. Екатеринбурга, полученные результаты свидетельствуют о том, что даже при длитель- ной эксплуатации разработанная установка не заселяется патогенными микроорганизмами.

\section{Заключение}

Химические, микробиологические и органолептические исследования показали, что обработанная с использованием малогабаритной установки вода из сети холодного водоснабжения полностью соответствует действующему ГОСТ Р 57164-2016 в области качества и безопасности питьевой воды. Аналогичная технология многоступенчатой очистки воды с частичной деминерализацией успешно масштабируется для предприятий пищевых производств любой производительности, но для отдельных видов пищевых продуктов требуется уточнять оптимальное содержание в воде минеральных веществ.

Основной акцент при проведении испытаний был сделан на устранение избыточной негативной минерализации питьевой водопроводной воды с последующим обогащением необходимыми макро- и микроэлементами, что позволяет улучшить как ее химические, так и органолептические характеристики.

Предлагаемая мембранная установка позволяет регулировать на выходе минеральный состав очищаемой водопроводной воды холодного водоснабжения в соответствии не только с требованиями СанПиН 2.1.4.1074-01, но и нормами, рекомендуемыми ВОЗ. 


\section{Библиографический список}

1. Свитцов А.А., Копылова Л.Е., Голованева Н.В. Особенности комбинированного реагентно-мембранного метода очистки минерализованных вод // Водоочистка. Водоподготовка. Водоснабжение. 2015. № 5 (89). С. 28-31.

2. Grachev V.A., Imran A., Alharbi Omar M.L, Tkachev A., Galunin E., Burakov A. Water treatment by new-generation graphene materials: hope for bright future // Environmental Science and Pollution Research. Kluwer Academic Publishers. 2018. T. 25. Pp. 7315-7329.

3. Lazarev V.A., Pastushkova Y.V., Chugunova O.V. Zero waste membrane technology for whey processing // Indian Journal of Science and Technology. 2016. T. 9, № 27. Pp. 207-216.

4. Timkin V.A., Lazarev V.A. Determination of the osmotic pressure of multicomponent solutions in the food industry // Petroleum Chemistry. 2015. T. 55, № 4. Pp. 301-307.

5. Богданов Б.А., Егорова Е.Ю., Зайнуллин Р.А. Водоподготовка в производстве пищевых продуктов и напитков / под общ. ред. Р.А. Зайнуллина. СПб.: Профессия, 2014. 398 с.

6. Свитцов А.А. Мембранные технологии в России // Водоснабжение и канализация. 2012. № 11-12. С. 42-48.

7. Хабибова Н.3., Копылова Л.Е., Свитцов А.А. Очистка воды мем6ранной экстракцией // Водоочистка. Водоподготовка. Водоснабжение. 2015. № 9 (93). С. 18-21.

8. Лазарев В.А., Мирошникова Е.Г., Пищиков Г.Б. Малогабаритная установка финальной доочистки воды с частичной деминерализацией для лабораторных нужд // Индустрия питания. 2018. T. 3, № 4. С. 74-84.

9. Тимкин В.А., Лазарев В.А. Определение осмотического давления многокомпонентных растворов пищевой промышленности // Мембраны и мембранные технологии. 2015. Т. 5, № 1. С. 48.

10. Svittsov A.A., Khubetsov S.B., Volchek K. Membrane treatment of liquid wastes from radiological decontamination operations // Water science and technology. Elsevier Science Publishing Company, Inc. 2011. T.64, № 4. Pp. 854-860.

11. Thick-Film Graphite Electrodes in Stripping Voltammetry / Brainina Kh., Stojko N., Malakhova N., Henze G., Faller C. // Fresenius' Journal of Analytical Chemistry. 1999. T. 364, № 4. Pp. 285-295.

12. Брайнина Х.З., Стожко Н.Ю., Малахова Н.А., Иванова А.В. Вольтамперометрические сенсоры для оn-site анализа // Микросистемная техника. 2002. № 2. С. 10-14.

\section{Bibliography}

1. Svitsov, A.A.; Kopylova, L.E.; Golovaneva, N.V. Osobennosti Kombinirovannogo Reagentno-Membrannogo Metoda Ochistki Mineralizovannykh Vod [Features of the Combined Reagent-Membrane Method of Purification of Salty Water]. Vodoochistka. Vodopodgotovka. Vodosnabzhenie. 2015. No. 5 (89). Pp. 28-31.

2. Grachev, V.A.; Imran, A.; Alharbi Omar, M.L; Tkachev, A.; Galunin, E.; Burakov, A. Water treatment by new-generation graphene materials: hope for bright future. Environmental Science and Pollution Research. Kluwer Academic Publishers. 2018. T. 25. Pp. 7315-7329.

3. Lazarev, V.A.; Pastushkova, Y.V.; Chugunova, 0.V. Zero waste membrane technology for whey processing. Indian Journal of Science and Technology. 2016. T. 9, № 27. Pp. 207-216.

4. Timkin, V.A.; Lazarev, V.A. Determination of the osmotic pressure of multicomponent solutions in the food industry. Petroleum Chemistry. 2015. T. 55, № 4. Pp. 301-307.

5. Bogdanov, B.A.; Egorova, E.Yu.; Zaynullin, R.A. Vodopodgotovka v Proizvodstve Pishchevykh Produktov i Napitkov [Water Treatment in Food and Beverage]. Pod obshch. red. Zainullina, R.A. SPb; Professiia, 2014. 398 p.

6. Svitsov, A.A. Membrannye Tekhnologii v Rossii [Membrane Technology in Water and Sanitation]. Vodosnabzhenie i Kanalizatsiia. 2012. No. 11-12. Pp. 42-48.

7. Habibov, N.Z.; Kopylova, L.E.; Svitsov, A.A. Ochistka vody membrannoi ekstraktsiei [Water Purification by the Membrane Extraction]. Vodoochistka. Vodopodgotovka. Vodosnabzhenie. 2015. №. 9 (93). Pp. 18-21.

8. Lazarev, V.A.; Miroshnikova, E.G.; Pishchikov, G.B. Malogabaritnaia Ustanovka Finalnoi Doochistki Vody s Chastichnoi Demineralizatsiei dlia Laboratornykh Nuzhd [Small-Size Equipment of Final Water Treatment with Partial Demineralization for Laboratory Needs]. Industriya Pitaniya. 2018. Vol. 3, No. 4. Pp. 74-84.

9. Timkin, V.A.; Lazarev, V.A. Opredelenie Osmoticheskogo Davleniia Mnogokomponentnykh Rastvorov Pishchevoi Promyshlennosti [Osmotic Pressure Determination of Multicomponent Solutions of Food Industry]. Membrany i Membrannye Tekhnologii. 2015. Vol. 5, No. 1. P. 48.

10. Svittsov A.A., Khubetsov S.B., Volchek K. Membrane treatment of liquid wastes from radiological decontamination operations // Water science and technology. Elsevier Science Publishing Company, Inc. 2011. T.64, № 4. Pp. 854-860.

11. Thick-Film Graphite Electrodes in Stripping Voltammetry. Brainina, Kh.; Stojko, N.; Malakhova, N.; Henze, G.; Faller, C. Fresenius' Journal of Analytical Chemistry. 1999. T. 364, № 4. Pp. 285-295.

12. Brainina, Kh.Z.; Stojko, N.Yu.; Malakhova, N.A.; Ivanova, N.A. Volt-Amperometricheskie Sensory dlia On-Site Analiza [Voltammetric Sensors for On-Site Analysis]. Mikrosistemnaia Tekhnika. 2002. № 2. Pp. 10-14. 


\section{Информация 06 авторах / Information about Authors}

\section{Лазарев \\ Владимир Александрович}

\section{Lazarev,}

Vladimir Aleksandrovich

тел./Phone: +7 (343) 221-17-26

E-mail: lazarev.eka@gmail.com

\section{Мирошникова \\ Елена Геннадьевна \\ Miroshnikova, \\ Elena Gennadjevna}

тел./Phone: +7 (343) 221-27-13

E-mail:meg_304@usue.ru
Кандидат технических наук, дочент кафедры пищевой инженерии

Уральский государственный экономический университет

620144, Российская Федерация, г. Екатеринбург, ул. 8 Марта/Народной Воли, 62/45

Candidate of Technical Science, Associate Professor of the Food Engineering Department Ural State University of Economics 620144, Russian Federation, Ekaterinburg, 8 March St. / Narodnoy Voli St., 62/45

ORCID: https://orcid.org/0000-0002-0470-7324

Кандидат химических наук, доцент, доцент кафедры физики и химии Уральский государственный экономический университет 620144, Российская Федерация, г. Екатеринбург, ул. 8 Марта/Народной Воли, 62/45

Candidate of Chemical Science, Associate Professor, Associate Professor of the Physics and Chemistry Department

Ural State University of Economics

620144, Russian Federation, Ekaterinburg, 8 March St. / Narodnoy Voli St., 62/45

ORCID: https://orcid.org/0000-0002-9916-4923 